\title{
Noradrenergic Innervation of the Dorsal Medial Prefrontal Cortex Modulates Hypothalamo-Pituitary-Adrenal Responses to Acute Emotional Stress
}

\author{
Jason J. Radley, Brandon Williams, and Paul E. Sawchenko \\ Laboratory of Neuronal Structure and Function, The Salk Institute for Biological Studies, and Clayton Medical Research Foundation, La Jolla, California \\ 92037
}

The medial prefrontal cortex (mPFC) has been proposed to play a role in the inhibition of hypothalamo-pituitary-adrenal (HPA) responses to emotional stress via influences on neuroendocrine effector mechanisms housed in the paraventricular hypothalamic nucleus (PVH). Previous work also suggests an involvement of the locus ceruleus (LC) in behavioral and neuroendocrine responses to a variety of acute stressors. The LC issues a widespread set of noradrenergic projections, and its innervation of the prefrontal cortex plays an important role in the modulation of working memory and attention. Because these operations are likely to be critical for stimulus selection, evaluation, and comparison with past experience in mounting adaptive responses to emotional stress, it follows that the LC-to-mPFC pathway might also be involved in regulating HPA activity under such conditions. Therefore, in the present study, we assessed the effects of selectively ablating noradrenergic inputs into the mPFC, using the axonally transported catecholamine immunotoxin, saporin-conjugated antiserum to dopamine- $\beta$-hydroxylase, on acute restraint stress-induced activation of HPA output. Immunotoxin injections in the dorsal mPFC (centered in the prelimbic cortex) attenuated increments in restraint-induced Fos and corticotropinreleasing factor mRNA expression in the neurosecretory region of PVH, as well as HPA secretory responses. Stress-induced Fos expression in dorsal mPFC was enhanced after noradrenergic deafferentation and was negatively correlated with stress-induced PVH activation, independent of lesion status. These findings identify the LC as an upstream component of a circuitry providing for dorsal mPFC modulation of emotional stress-induced HPA activation.

Key words: ACTH; CRF; dopamine- $\beta$-hydroxylase; Fos; HPA axis; hypothalamus; immunotoxin; locus ceruleus (coeruleus); norepinephrine; paraventricular nucleus; saporin

\section{Introduction}

The medial prefrontal cortex (mPFC) plays an important role in modulating hypothalamo-pituitary-adrenal (HPA) responses to emotional stress (Diorio et al., 1993; Figueiredo et al., 2003; Radley et al., 2006). Such influences are mediated via corticotropinreleasing factor (CRF)-expressing parvicellular neurosecretory neurons in the paraventricular hypothalamic nucleus $(\mathrm{PVH})$, which initiate the HPA cascade by stimulating the release of adrenocorticotropic hormone $(\mathrm{ACTH})$, which, in turn, activates adrenal glucocorticoid secretion (Antoni, 1986). The HPA axis functions in concert with the sympathoadrenal system in mobi-

\footnotetext{
Received Feb. 6, 2008; revised March 28, 2008; accepted April 18, 2008.

This work was supported by National Institutes of Health Grant NS-49196 and was conducted in part by the Clayton Medical Research Foundation. P.E.S. is an Investigator of the Clayton Medical Research Foundation. J.J.R. was supported by the Anxiety Disorders Association of America and National Alliance for Research on Schizophrenia and Depression Young Investigator grants. We thank J. Vaughn for generating the Fos antiserum and Drs. J. Serrats and R. Rissman for antiserum characterization and helpful discussions. We also thank Casey Peto for help in photomicroscopy, Kris Trulock for help in the preparation of the illustrations, Belle Wamsley for editorial assistance, Carlos Arias for technical assistance, and Yaira Haas for assistance with radioimmunoassays.

Correspondence should be addressed to either Jason J. Radley or Paul E. Sawchenko, 10010 North Torrey Pines Road, La Jolla, CA 92037. E-mail: radley@salk.edu or sawchenko@salk.edu.

D0I:10.1523/JNEUROSCI.0552-08.2008

Copyright $\odot 2008$ Society for Neuroscience $\quad$ 0270-6474/08/285806-11\$15.00/0
}

lizing and redirecting bodily resources to facilitate "fight-orflight" responses.

The locus ceruleus (LC) is the principal noradrenergic cell group in brain and plays established roles in promoting behavioral adaptations to a variety of alerting stimuli, including stressful ones (Aston-Jones et al., 1996; Sved et al., 2002; Berridge and Waterhouse, 2003; Morilak et al., 2005). In line with this, several studies have found that lesions or pharmacologic silencing of the LC attenuate HPA responses to emotional stressors (Ziegler et al., 1999; Passerin et al., 2000). Although such work suggests that LC facilitates HPA responses to emotional stress, its lack of any substantial innervation of PVH (Sawchenko and Swanson, 1981, 1982; Cunningham and Sawchenko, 1988) raises the possibility that the influence of LC on stress-induced HPA activation might be mediated indirectly, through its projections to limbic and forebrain regions implicated in HPA control (Ziegler et al., 1999).

The $\mathrm{mPFC}$ is involved in the regulation cognitive and emotional processing (Bush et al., 2000), and the LC noradrenergic projections to this region have modulatory effects on working memory and attention (Aston-Jones et al., 2000; Kerns et al., 2004; Milstein et al., 2007; Ramos and Arnsten, 2007). These operations are likely to be important for the capacity of mPFC to evaluate the contextual relevance and emotional valence of po- 
tentially threatening stimuli for mounting adaptive responses. Nonetheless, the involvement of the LC-to-mPFC pathway in HPA regulation has not been tested and is problematic because dorsal mPFC ( $\mathrm{mPFCd}$ ) lesions have been shown to enhance (Diorio et al., 1993; Figueiredo et al., 2003; Radley et al., 2006), whereas LC lesions attenuate (Ziegler et al., 1999), HPA activation in response to acute emotional stressors.

The purpose of this study was to examine the extent to which HPA-facilitatory influences of LC may be effected via its projections to mPFCd. This was achieved by comparing the effects of selectively lesioning noradrenergic inputs to the mPFCd on indices of acute stress-induced PVH activation (Fos protein, CRF mRNA) and pituitary-adrenal hormonal output. Lesions were performed by the focal administration of an axonally transported immunotoxin, anti-dopamine- $\beta$-hydroxylase-saporin (anti$\mathrm{DBH}$-saporin), which targets specifically noradrenergic terminals and the neurons that give rise to them (Wrenn et al., 1996; Ritter et al., 2001, 2003). Ancillary analyses were also performed to assess the impact of noradrenergic denervation of mPFCd on stress-induced activational responses in both the MPFC and LC.

Parts of this work have been reported previously in abstract form (Radley and Sawchenko, 2007).

\section{Materials and Methods}

Animals and treatments. Adult male Sprague Dawley albino rats (275-325 g) were used in all experiments. They were housed individually in a temperature-controlled room on a $12 \mathrm{~h}$ light/dark cycle with the lights on at 6:00 A.M. Food (rodent chow 8604; Harland Teklad) and water were available ad libitum. Rats were adapted to handling for at least $3 \mathrm{~d}$ before any manipulation. All experimental protocols were approved by the Institutional Animal Care and Use Committee of the Salk Institute.

The basic protocol involved subjecting separate groups of rats to bilateral injections of immunotoxin into the dorsal mPFC, or sham injections. After a $14 \mathrm{~d}$ recovery period, rats were restrained at 9:00 A.M. in plastic restrainers (Braintree Scientific) for $30 \mathrm{~min}$. Controls were handled comparably but were not restrained. All animals remained in their home cages during and after restraint until the prescribed time of perfusion for histology ( $2 \mathrm{~h}$ after the termination of restraint) or during collection of repeated blood samples.

Immunotoxin lesions. To selectively ablate noradrenergic neurons that project to $\mathrm{mPFCd}$, anti-DBH-saporin (conjugates of saporin with a monoclonal antibody against dopamine- $\beta$-hydroxylase; Advanced Targeting Systems) were bilaterally microinjected into this cortical field. The antibody used in generating the conjugate is the same one used for immunohistochemistry (see below). A stock solution $(1.9 \mathrm{mg} / \mathrm{ml})$ was diluted 1:4 in artificial CSF ( $\mathrm{aCSF}$ ) composed of the following (in mM): 124 $\mathrm{NaCl}, 5 \mathrm{KCl}, 2.4 \mathrm{CaCl}_{2}, 1.3 \mathrm{MgSO}_{4}, 1.24 \mathrm{KH}_{2} \mathrm{PO}_{4}, 26 \mathrm{NaHCO}_{3}$, and 10 $\alpha$-D-glucose at $\mathrm{pH}$ 7.4. Injections were placed via micropipettes (10-20 $\mu \mathrm{m}$, inner diameter) using pressure ejection (World Precision Instruments) to deliver $90-120 \mathrm{nl} /$ side at the following stereotaxic coordinates: anteroposterior, $+2.90 \mathrm{~mm}$; mediolateral, $\pm 0.75 \mathrm{~mm}$; dorsoventral, $-2.50 \mathrm{~mm}$. Sham lesions involved either injecting saporin conjugated to IgG or the aCSF vehicle. The extent and specificity of damage was estimated by reconstruction from material stained for DBH and/or tyrosine hydroxylase (TH) (see below) (see Figs. 1, 2). In addition, a series of sections through the LC were examined for loss of DBH-immunostained and/or stress-sensitive neurons that give rise to this projection (see below).

Histology and tissue processing. Rats were anesthetized with chloral hydrate $(350 \mathrm{mg} / \mathrm{kg}$, i.p.) and perfused via the ascending aorta with 100 $\mathrm{ml}$ of $0.9 \%$ saline, followed by $900 \mathrm{ml}$ of ice-cold $4 \%$ paraformaldehyde in $0.1 \mathrm{M}$ borate buffer, $\mathrm{pH} 9.5$, at a flow rate of $55 \mathrm{ml} / \mathrm{min}$. The brains were removed, postfixed for $3 \mathrm{~h}$, and cryoprotected in $20 \%$ sucrose in $0.1 \mathrm{M}$ phosphate buffer overnight at $4^{\circ} \mathrm{C}$. Five one-in-five series of $30-\mu \mathrm{m}$ thick frozen coronal sections through the entire brain were cut and collected in cryoprotectant solution and stored at $-20^{\circ} \mathrm{C}$ until processing.

Antibodies. The Fos antiserum was generated in our laboratory and was used in all experiments at a dilution of 1:50,000. A peptide fragment corresponding to amino acids 4-17 (SGFNADYEASSSRC) of rat Fos was generously provided and synthesized by Dr. Jean Rivier (The Salk Institute, La Jolla, CA) using solid phase methodology. It was purified by HPLC and characterized using mass spectrometry. The antiserum against Fos was raised in rabbits immunized against the synthetic peptide fragment coupled to keyhole limpet hemocyanin using a protocol described previously (Vaughan et al., 1989). The antiserum was characterized in Northern blots of extracts from brain regions of stressed and unmanipulated rats, and its specificity was supported in experiments in which preabsorption overnight at $4^{\circ} \mathrm{C}$ with $7 \mu \mathrm{M}$ of the synthetic peptide immunogen eliminated staining in control and experimental tissue. $\mathrm{DBH}$ was detected by using a monoclonal antibody raised against bovine adrenal DBH (catalog number MAB308, clone 4F10.2; Millipore Bioscience Research Reagents). Localization of TH was achieved using a rabbit polyclonal antiserum raised against recombinant bovine or rat $\mathrm{TH}$ (catalog number P40101-0; Pel-Freez Biologicals). Specificities of the latter antisera were established by comparison of labeling patterns with immunoreactivity and hybridization histochemical localization for respective mRNA in material from the same animals over a range of challenge conditions (data not shown).

Immunohistochemistry. All immunohistochemical procedures were performed on free-floating sections, involving initial treatment in $10 \mathrm{~min}$ with $0.3 \%$ hydrogen peroxide to neutralize endogenous peroxidases, followed by $8 \mathrm{~min}$ exposure to $0.5 \%$ sodium borohydride to reduce free aldehydes. DBH or Fos immunolocalization was performed using a conventional avidin-biotin peroxidase technique (Sawchenko et al., 1990). Sections were incubated in Fos or DBH antisera at $4^{\circ} \mathrm{C}$ for $48 \mathrm{~h}$ in PBS containing $0.3 \%$ Triton X-100 and 3\% blocking serum. The primary antiserum was localized using Vectastain Elite reagents (Vector Laboratories), and the reaction product was developed using a nickel-enhanced glucose oxidase method (Shu et al., 1988). Dual immunoperoxidase labeling for Fos and DBH was performed by sequentially localizing the antiserum against Fos using a nickel-enhanced diaminobenzidine method (black nuclear reaction product) as above and the antiserum to $\mathrm{DBH}$, without nickel enhancement (brown cytoplasmic product). Dual immunofluorescence for DBH and TH was performed by incubating sections in mouse anti-DBH (Millipore Bioscience Research Reagents; see above) and rabbit anti-TH at $4^{\circ} \mathrm{C}$ for $48 \mathrm{~h}$ in PBS containing $0.3 \%$ Triton X-100 and 3\% blocking serum. Primary antisera for DBH and TH were detected using a species-specific anti-mouse IgG coupled to Alexa Fluor 488 and anti-rabbit IgG coupled to Alexa Fluor 568 (Invitrogen).

Hybridization histochemistry. Techniques for probe synthesis, hybridization, and autoradiographic localization of mRNA signal were adapted from Simmons et al. (1989). In situ hybridization was performed using ${ }^{35}$ S-labeled sense (control) and antisense cRNA probes labeled to similar specific activities using a full-length $(1.2 \mathrm{~kb})$ probe for mRNA encoding CRF (1.2 kb; Dr. K. Mayo, Northwestern University, Evanston, IL). Sections were mounted onto poly-L-lysine-coated slides and dried under vacuum overnight. They were postfixed with $10 \%$ paraformaldehyde for $30 \mathrm{~min}$ at room temperature, digested with $10 \mu \mathrm{g} / \mathrm{ml}$ proteinase $\mathrm{K}$ for 15 $\mathrm{min}$ at $37^{\circ} \mathrm{C}$, and acetylated for $10 \mathrm{~min}$. Probes were labeled to specific activities of $1-3 \times 10^{9} \mathrm{dpm} / \mu \mathrm{g}$ and applied to the slides at concentrations of $\sim 10^{7} \mathrm{cpm} / \mathrm{ml}$, overnight at $56^{\circ} \mathrm{C}$ in a solution containing $50 \%$ formamide, $0.3 \mathrm{~m} \mathrm{NaCl}, 10 \mathrm{~mm}$ Tris, $1 \mathrm{~mm}$ EDTA, 0.05\% tRNA, $10 \mathrm{~mm}$ dithiothreitol, $1 \times$ Denhardt's solution, and $10 \%$ dextran sulfate, after which they were treated with $20 \mu \mathrm{g} / \mathrm{ml}$ ribonuclease A for $30 \mathrm{~min}$ at $37^{\circ} \mathrm{C}$ and washed in $15 \mathrm{~mm} \mathrm{NaCl} / 1.5 \mathrm{~mm}$ sodium citrate with $50 \%$ formamide at $70^{\circ} \mathrm{C}$. Slides were then dehydrated and exposed to $\mathrm{x}$-ray films (Kodak Biomax MR; Eastman Kodak) for 18 h. They were coated with Kodak NTB-2 liquid emulsion and exposed at $4^{\circ} \mathrm{C}$ for 3-4 weeks, as determined by the strength of signal on film. Slides were developed with Kodak D-19 and fixed with Kodak rapid fixer.

Hormone assays. Separate groups of animals were implanted with indwelling jugular catheters $12 \mathrm{~d}$ after receiving immunotoxin or sham lesions to mPFCd and $2 \mathrm{~d}$ before stress exposure. The procedures for implanting catheters have been described previously (Ericsson et al., 1994; Schiltz and Sawchenko, 2002). Briefly, catheters (polyethylene 50) containing sterile heparin-saline $(50 \mathrm{U} / \mathrm{ml})$ were implanted under ket- 
amine-xylazine-acepromazine anesthesia (25:5:1 mg/kg, s.c.). The sealed catheter was positioned with its internal SILASTIC (Dow Corning) tip at the atrium and was exteriorized in an interscapular position. Blood samples $(300 \mu \mathrm{l})$ were taken before restraint stress to estimate basal ACTH and corticosterone levels. Additional samples were collected at 0, 30, 60, 90, and 120 min after the termination of restraint. Samples were collected into chilled EDTAcontaining tubes and centrifuged; plasma was stored at $-20^{\circ} \mathrm{C}$ until assay. ACTH was measured using a two-site immunoradiometric assay obtained in kit form (DiaSorin), with intraassay and interassay coefficients of variation of 3 and $9 \%$, respectively, and a sensitivity of $5 \mathrm{pg} /$ $\mathrm{ml}$. Plasma corticosterone was measured without extraction, using an antiserum raised in rabbits against a corticosterone-BSA conjugate and $\left[{ }^{125} \mathrm{I}\right]$ corticosterone-BSA as tracer (MP Biomedicals). The sensitivity of the assay was 0.8 $\mu \mathrm{g} / \mathrm{dl}$; intra-assay and interassay coefficients of variation were 5 and $10 \%$, respectively.

Data analysis. Stereological methods were used to quantify the number of Fosimmunoreactive neurons in the PVH and prelimbic (PL) and infralimbic (IL) subdivisions of the mPFC. These analyses were performed using a computer-assisted morphometry system consisting of a photomicroscope equipped with an $x y z$ computer-controlled motorized stage, MicroFire camera (Optronics), Gateway microcomputer, and StereoInvestigator morphometry and stereology software (MBF Biosciences). For each analysis, boundaries defining the regions of interest were drawn at $25 \times$ using an adjacent series of Nissl-stained sections. Analyses of Fos-immunoreactive cells were performed on every fifth section, avoiding cells in the outermost plane of focus. Counts were then multiplied by five to estimate the total number of labeled neurons in the defined region of interest.

Numbers of Fos-immunoreactive cells in PL and IL were estimated using the optical fractionator method (Gundersen et al., 1988). Optical disector counting frames were placed in a random manner within the delineated regions with constant intervals in the $x$ - and $y$-axes in every fifth section throughout the entire rostrocaudal extent of the structure. The $x$ and $y$ distances between sampling frames were set at 250 $\mu \mathrm{m}$ for the PL and $150 \mu \mathrm{m}$ for IL. The counting
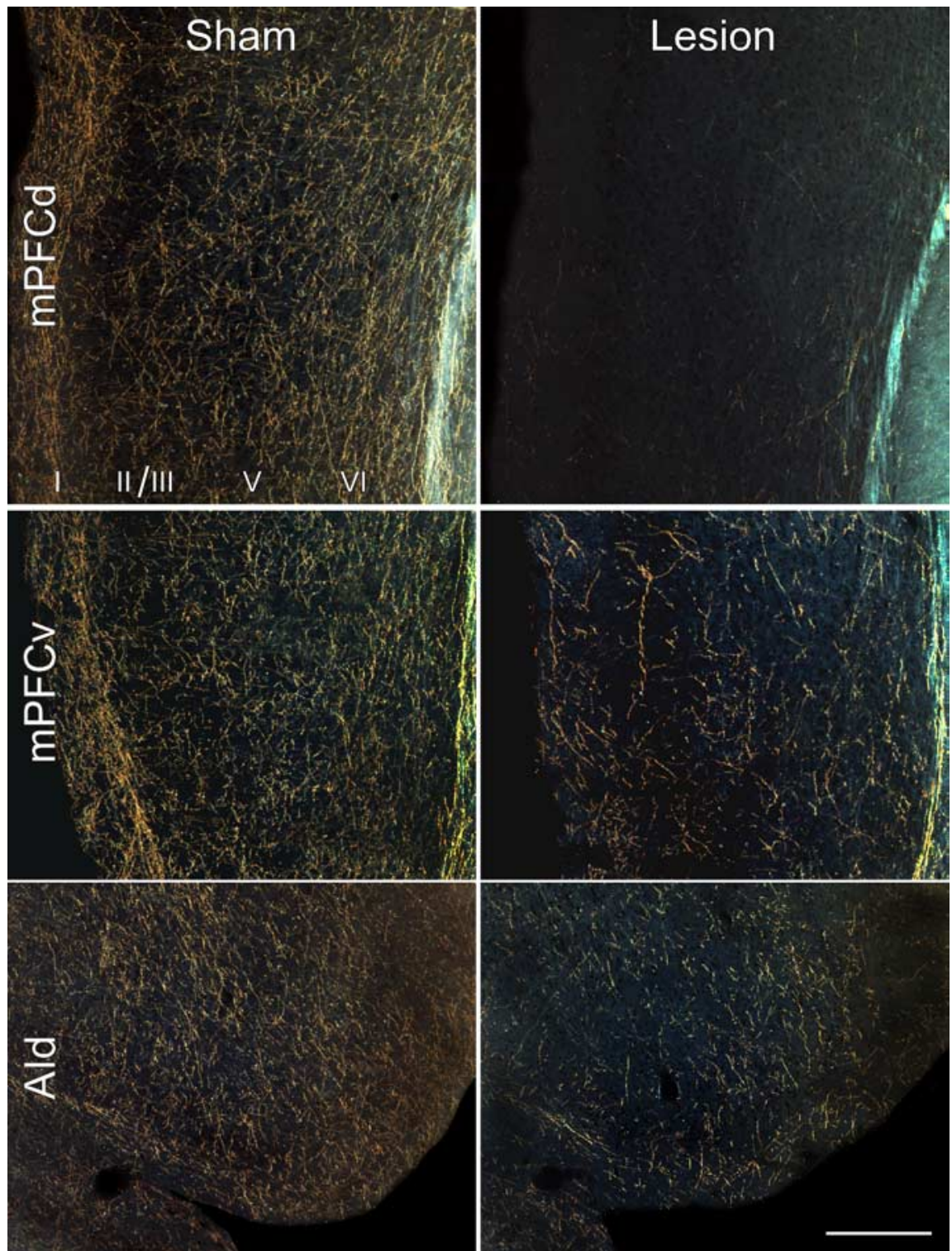

Figure 1. Noradrenergic denervation after anti-DBH-saporin injections in mPFCd. Dark-field photomicrographs showing DBH immunostaining as a function of lesion status. Top row, Immunotoxin or sham injections were centered in the prelimbic area of the mPFC. Anti-DBH-saporin injections virtually eliminate all noradrenergic fibers and terminals throughout the mPFCd, whereas control injections of the untargeted toxin (IgG-saporin) leave these inputs intact. Middle, bottom rows, A partial depletion of noradrenergic fibers and terminals in adjacent cortical structures was observed after anti-DBH-saporin injections into the prelimbic area, consistent with reports of collateralization of prelimbic-projecting LC neurons to adjacent cortical fields. Ald, Agranular insular cortex, dorsal subdivision. Scale bar, $250 \mu \mathrm{m}$ (applies to all).

frame width and height was $100 \mu \mathrm{m}$, and the

$z$-axis thickness of the counting frame was $10 \mu \mathrm{m}$. The area sampling fraction was $(100 \times 100 \mu \mathrm{m}) /(250 \times 250 \mu \mathrm{m})=100 / 625$ for PL and $100 / 225$ for IL. The coefficients of error for each stereological estimate were determined prospectively as described previously (Schmitz and Hof, 2000).

Volumes estimates were obtained from cross-sectional area measurements using the Cavalieri method to assess for possible treatment effects in PVH, PL, IL, and LC. To further clarify the effects of immunotoxin on the total population of noradrenergic neurons in LC, DBH-stained neurons (and those double labeled for Fos protein) were counted manually throughout the LC in every fifth section. Because the section thickness was too small relative to the average diameter of DBH-stained neurons in LC to permit stereologic approaches, estimates of total numbers were obtained using the Abercrombie correction (Abercrombie, 1949).

Semiquantitative densitometric analysis of relative levels of CRF mRNA was performed on emulsion-coated slides using NIH Image J soft- ware. The optical densities of hybridization signals were determined under dark-field illumination at $100 \times$ magnification. The hypophysyiotropic PVH (i.e., dorsal medial parvicellular subdivision) was defined from Nissl staining pattern (Swanson and Kuypers, 1980) and aligned with corresponding dark-field images of hybridized sections by redirected sampling. Optical density readings, corrected for background, were taken at regularly spaced $(150 \mu \mathrm{m})$ intervals, and average values were determined through the extent of this cell group for each animal. Images from CRF mRNA densitometry were collected using a Hamamatsu Orca CCD camera under the control of OpenLab software (version 3.1.5). Images collected from each analysis were exported first to Adobe PhotoShop (version 7) for adjustments to optimize/balance contrast and brightness and then to Canvas (version 8) for assembly and labeling.

Statistics. Grouped data from the immunoperoxidase $(n=6$ per group) and hybridization histochemical analyses ( $n=4$ per group) were compared with a one-way ANOVA for lesion and treatment (sham + 

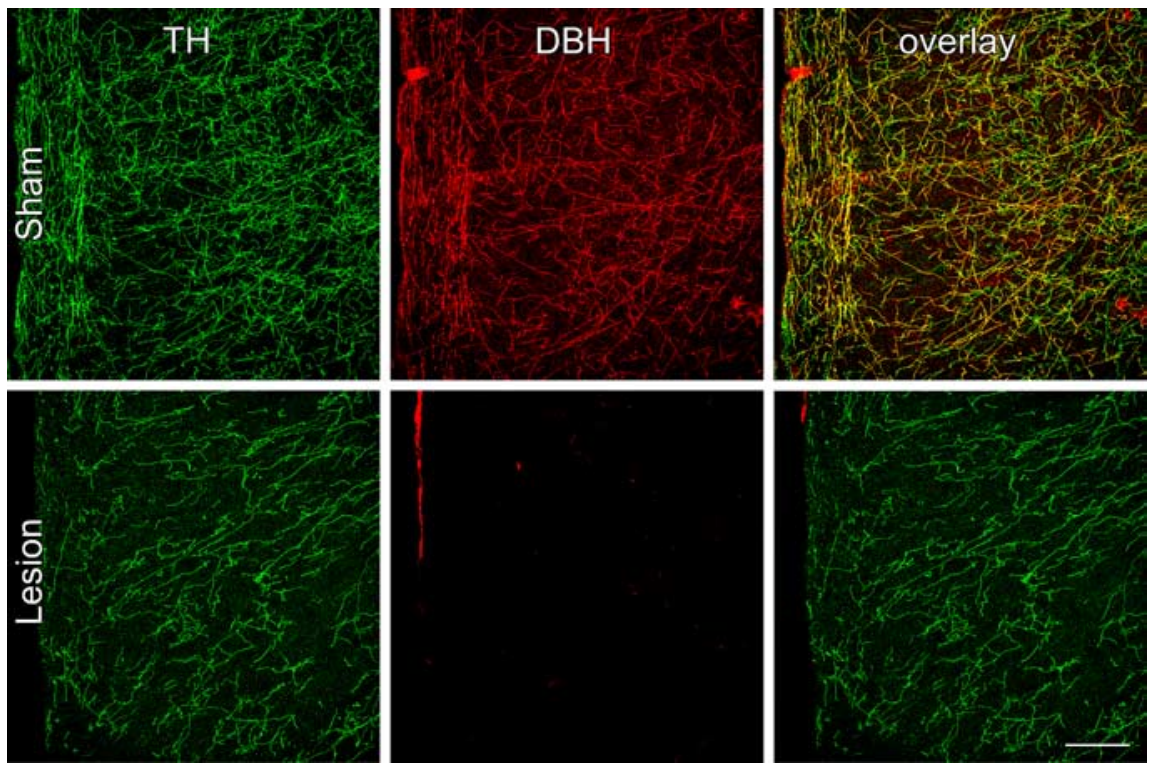

Figure 2. Neurochemical specificity of immunotoxin-mediated denervation in mPFCd. The specificity of noradrenergic deafferentation of the mPFCd was assessed by evaluating the extent to which immunotoxin injection affected dopaminergic fibers and terminals. Confocal images of dual immunofluorescence preparations show TH (green, left column) and DBH (red, middle column) fiber and terminal labeling in the prelimbic area. Because TH is required for the synthesis of DA and NE, the immunolabeling profile for this enzyme represents both DA and NE fibers and terminals, whereas immunolabeling for DBH is specific to NE. In sham-lesioned animals (top row), the overlay of TH- and DBH-stained fibers (right, yellow) represents the subset of inputs that are dopaminergic, whereas the DA fibers display only TH labeling (green). After anti-DBH-saporin injections into the prelimbic area, the density of fibers and varicosities labeled for TH only is comparable with controls, whereas there is a near elimination of DBH staining in the mPFCd (middle), reflected in the absence of elements that would normally be double labeled for both enzymes (right). Scale bar, $250 \mu \mathrm{m}$ (applies to all).

control, sham + stress, and lesion + stress) status, followed by post hoc pairwise comparisons using a Bonferroni's correction. Group data from the hormone assays were compared with a mixed-design ANOVA with one within-group (time) and one between-group (lesion status; $n=5$ per group) variable, followed by individual pairwise comparisons as above. The total integrated ACTH and corticosterone responses were also expressed as area under the curve measures for overall group differences and were subject to $t$ tests for statistical comparison. Data were expressed as the mean + or \pm SEM.

\section{Results}

\section{Extent and specificity of noradrenergic denervation}

The placement and extent of immunotoxin lesions to mPFCd was evaluated in DBH-immunostained material, using adjoining series of Nissl-stained sections to permit referencing to standard cytoarchitectonic parcellation of this region (Krettek and Price, 1977; Vogt and Peters, 1981). Stereotaxic coordinates for mPFCd injections were derived from previous microinjection studies (Radley et al., 2006). mPFCd immunotoxin injections were centered in PL and typically spread to ventral portions of dorsal anterior cingulate cortex and, to a lesser extent, caudally into the ventral anterior cingulate area, immediately dorsal to the genu of the corpus callosum.

Anti-DBH-saporin injections virtually eliminated noradrenergic fibers and varicosities from the dorsal mPFC, whereas control injections of the untargeted toxin (IgG-saporin) or aCSF left these inputs intact (Fig. 1, top). No overt signs of damage or cell loss were evident after control or immunotoxin injections, apart from the circumscribed injury associated with the injector tract. Although the injection volumes were chosen to be small enough $(90-120 \mathrm{nl} / \mathrm{side})$ to limit the spread of immunotoxin to within the mPFCd, partial denervation of noradrenergic terminal fields was typically evident in adjoining prefrontal fields (Fig. 1, middle, bottom). This is consistent with the documented collateralization of prelimbicprojecting LC neurons to adjacent cortical fields (Morrison et al., 1979, 1981). The DBH-immunoreactive innervation of other cortical (hippocampus) and subcortical (amygdala, bed nucleus of the stria terminalis) cell groups implicated in HPA control were ostensibly unaffected by immunotoxin injections in mPFCd (supplemental Fig. 1, available at www.jneurosci. org as supplemental material), which is again consistent with previous work on the organization of LC projections (Mason and Fibiger, 1979; Loughlin et al., 1982).

The specificity of noradrenergic denervation of the mPFCd was assessed by examining the extent to which damage from the immunotoxin injection involved dopaminergic fibers and terminals in dual immunofluorescence preparations for $\mathrm{TH}$ and DBH (Fig. 2). TH converts tyrosine to dihydroxyphenylalanine, a precursor of both dopamine (DA) and norepinephrine (NE); immunolabeling for this enzyme represents both DA and NE fibers and terminals, whereas staining for DBH in cortex is specific to NE. Thus, the overlay of TH- and DBH-stained fibers and varicosities represents the subpopulation of inputs into mPFCd that are noradrenergic, whereas fibers single labeled for TH are dopaminergic (Fig. 2, top). After anti-DBH-saporin injections into PL, the density of dopaminergic (i.e., $\mathrm{TH}^{+} / \mathrm{DBH}^{-}$) fibers and varicosities was comparable with controls in density and distribution, whereas there was a near complete elimination of DBH staining in mPFCd, as well as of elements double labeled for both enzymes (Fig. 2, bottom).

\section{Effects of noradrenergic denervation of mPFCd on PVH activational responses to acute restraint}

We initially surveyed the effects of immunotoxin lesions in mPFCd on stress-induced expression of Fos protein, a generic marker of neuronal activation, in the PVH of animals killed $2 \mathrm{~h}$ after the termination of a single exposure to restraint stress. The $2 \mathrm{~h}$ time point represents the interval at which maximal Fos induction has been reported in this paradigm (Viau and Sawchenko, 2002). Consistent with previous observations that the catecholaminergic innervation of the $\mathrm{PVH}$ arises principally from medullary aminergic cell groups and not the LC (Sawchenko and Swanson, 1981, 1982), no frank differences were evident in DBH immunostaining in this region after immunotoxin lesions in mPFCd (Fig. 3, top). Acute stress resulted in a marked increase in Fos expression in sham-lesioned animals focused in the CRF-rich hypophysiotropic zone of $\mathrm{PVH}$, and this effect was reduced in animals bearing immunotoxin lesions (Fig. 3 , middle). Comparison of total numbers of Fos-activated cells in $\mathrm{PVH}$ revealed a overall significant effect $\left(F_{(2,15)}=29.5 ; p<\right.$ $0.0001)$. Individual comparisons revealed that values from stressed groups (sham + stress, lesion + stress) were significantly greater than those of unstressed, sham-lesioned controls $(p<$ 0.0001) (Fig. 3, bottom). Moreover, stress-induced Fos expression in the PVH was attenuated (by 28\%) in immunotoxin- 
lesioned animals compared with shamlesioned animals $(p<0.05)$. Although the design did not include lesioned, unstressed control groups, we prepared additional groups of immunotoxin- and shamlesioned rats for analysis of possible effects on basal Fos expression in PVH. The analysis (data not shown) failed to reveal any effects of lesion status on the number of Fos-immunoreactive neurons in $\mathrm{PVH}$ of unstressed rats.

Material from this same experiment was prepared for densitometric analysis of relative levels of CRF mRNA expression in $\mathrm{PVH}$, to obtain an independent assessment of lesion effects on an endpoint more directly related to HPA activity (Fig. 4, top). Comparisons of CRF mRNA signals in the $\mathrm{PVH}$ revealed a significant effect of treatment $\left(F_{(2,9)}=914.2 ; p<0.005\right)$. Consistent with the Fos expression data, restraint stress resulted in a twofold increase in CRF mRNA expression in the hypophysiotropic zone of PVH in sham-lesioned animals compared with unstressed controls $(p<0.001)$ (Fig. 4, bottom). This effect was again reliably diminished in immunotoxin-lesioned animals relative to sham-lesioned, stressed rats $(p<0.005)$, to levels that did not significantly differ from those of unstressed controls $(p=$ $0.7)$.

\section{Immunotoxin effects on stress hormone secretion}

HPA secretory responses before and during $30 \mathrm{~min}$ restraint stress were examined in separate groups of sham- and immunotoxin-lesioned animals (Fig. 5). Lesions in these experiments were similar in placement and extent to those described above. Mixed-design ANOVA of ACTH data, with time of blood sampling treated as a within-subjects factor, demonstrated effects of time $\left(F_{(5,8)}=5.3 ; p<0.001\right)$, although not of treatment status $\left(F_{(5,40)}=1.9 ; p=0.2\right)$ or of an interaction between these variables $\left(F_{(8,13)}=1.8 ; p=0.1\right)$. Despite differences in mean peak ACTH levels between groups, data from the sham-lesioned animals were variable, and these did not differ significantly. Nonetheless, there was a significant reduction (by 62\%; $p<0.05$ ) in total integrated plasma ACTH response in the lesioned compared with sham groups, assessed by calculating areas under the curve.

Plasma corticosterone levels showed reliable main effects of lesion status $\left(F_{(1,8)}=5.4 ; p<0.05\right)$ and time $\left(F_{(5,8)}=23.7 ; p<\right.$ $0.001)$ but not of the interaction term $\left(F_{(1,13)}=0.9 ; p=0.5\right)$. Sham and lesioned groups both displayed significant stressinduced increases in mean peak plasma corticosterone values that did not differ significantly $(646 \pm 79$ and $486 \pm 102 \mathrm{ng} / \mathrm{ml}$, respectively) at the peak $(30 \mathrm{~min})$ time point $(p=0.2)$, nor were there any significant differences at individual time points between sham and lesion groups. As with the ACTH data, however, there was a significant $(41 \% ; p<0.05)$ reduction in overall plasma corticosterone response in the lesioned group in area un- der the curve assessments. Immunotoxin-lesioned animals also displayed a more rapid recovery of stress-induced plasma corticosterone levels, being significantly elevated above baseline values at 30 and $60 \mathrm{~min}$ (both $p<0.05$ compared with $0 \mathrm{~min}$ ), whereas titers in sham-lesioned animals were significantly elevated through $90 \mathrm{~min}$ ( $p<0.05$ at 30,60, and $90 \mathrm{~min}$ ). Basal plasma levels of ACTH and corticosterone were not affected by the lesions ( $p=0.8$ and 0.9 , respectively), further suggesting that the effects of noradrenergic denervation in the dorsal mPFC are manifest during stress.

\section{Relationship between stress-induced activational responses in mPFCd and PVH}

The preceding analyses suggest that engagement of LC projections to mPFCd facilitates HPA output during acute emotional stress. Reconciling this with the established inhibitory nature of mPFCd regulation of HPA output (Diorio et al., 1993; Figueiredo et al., 2003; Radley et al., 2006) would require that the action of LC on mPFCd is also inhibitory; in other words, noradrenergic 

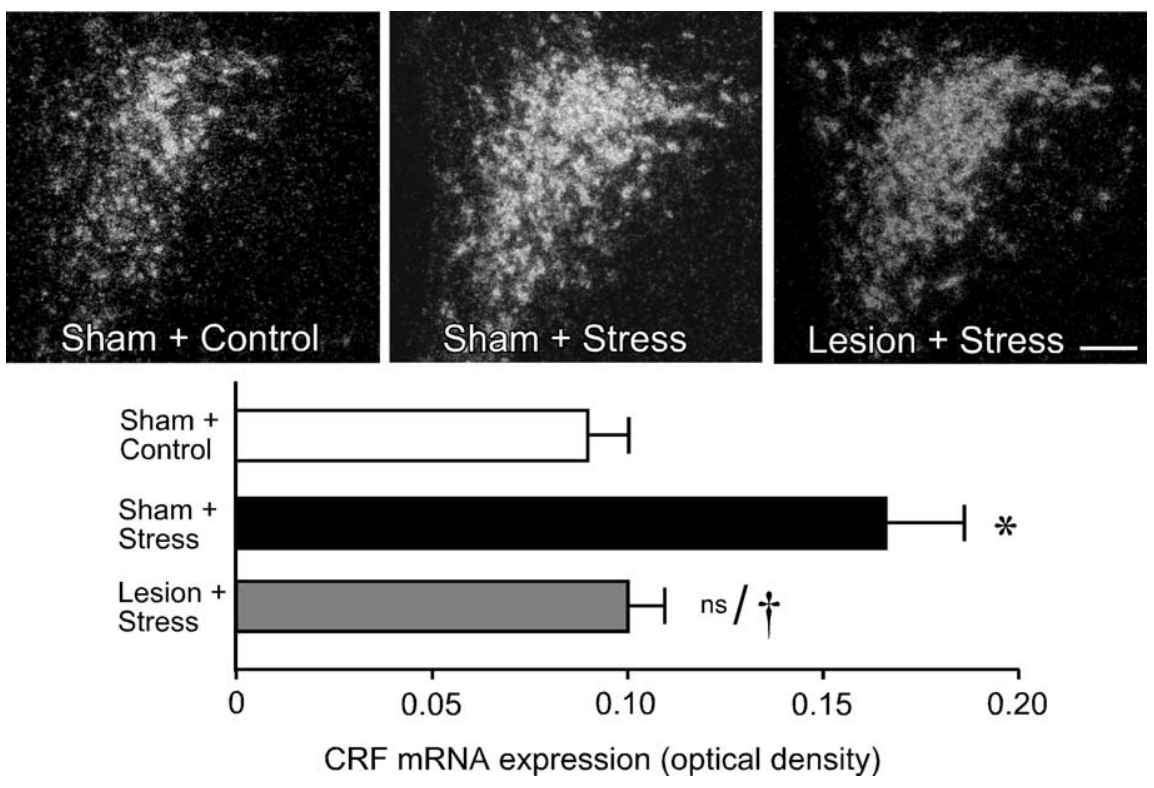

Figure 4. Effects of noradrenergic denervation of mPFCd on restraint-induced upregulation of CRF mRNA in PVH. Top, Darkfield photomicrographs showing CRF mRNA expression in the PVH as a function of treatment status. Relative to sham-lesioned unstressed animals, acute restraint exposure results in increased relative levels of CRF mRNA in the hypophysiotropic zone of the PVH. No such enhancement was seen in animals that received anti-DBH-saporin injections into mPFCd $14 \mathrm{~d}$ before stress. Bottom, Relative levels (mean + SEM) of CRF mRNA expression in the PVH in treatment groups. Stress exposure increases relative levels of CRF mRNA, whereas this effect is not observed after immunotoxin-mediated denervation of $\mathrm{mPFCd} .{ }^{*} p<0.05$, differs significantly from unstressed controls; ${ }^{\dagger} p<0.01$, differs significantly from sham-lesioned stressed animals; $\mathrm{ns}$, nonsignificant. $n=4$ per group. Scale bar, $200 \mu \mathrm{m}$ (applies to all).

denervation results in a disinhibition of mPFCd outputs, with consequent attenuation of PVH responses. To test this prediction, anti-DBH-saporin effects on restraint-induced Fos expression were assessed in PL (the major component of mPFCd) and, for comparison, in IL (which was partially denervated by immunotoxin injections). We found that acute restraint stress resulted in a $>2.5$-fold increase in the number of Fos-immunoreactive neurons in PL and IL (both $p$ values $<0.0001$ ), and this effect was reliably enhanced in PL (by $28 \%$ ) in animals receiving immunotoxin injections in mPFCd $(p<0.05)$ (Fig. 6, top). Moreover, plots of individual values from all animals subjected to acute restraint (regardless of lesion status) indicate that the degree of Fos activation in PL and PVH are inversely correlated $(r=-0.71$; $p<0.05)$. In contrast, no additional enhancement of stressinduced Fos expression in IL was seen in immunotoxin-lesioned animals $(p=0.2)$, nor was there a reliable correlation between Fos activation in IL and PVH $(r=-0.05 ; p=0.9)$ (Fig. 6, bottom).

\section{Immunotoxin effects on LC}

To determine whether and how immunotoxin lesions of mPFCd affect stress-induced activational responses in LC, tissue from sham- and immunotoxin-lesioned animals was prepared for dual immunostaining for Fos and DBH (Fig. 7). From extremely low basal levels of expression, 30 min restraint exposure resulted in a marked increase in the number of $\mathrm{DBH}$-immunoreactive LC neurons that exhibited nuclear Fos immunoreactivity $(p<$ 0.0001 ). Immunotoxin lesions resulted in an attenuation (by $37 \%)$ of this response $(p<0.05)$, suggesting a loss of stresssensitive, mPFC-projecting LC neurons. Furthermore, immunotoxin-lesioned rats displayed a corresponding decrease (by $23 \%$ ) in the total population of LC neurons $(568 \pm 29 \mathrm{DBH}-$ labeled cells per side) compared with sham-lesioned animals
$(736 \pm 50 \mathrm{DBH}$-labeled cells per side; $p<$ 0.05 ) and a reduction in volume (by $25 \%$; $p<0.05)$.

The interpretation of the above findings may be complicated by evidence supporting the existence of a return projection from mPFC to LC (Luppi et al., 1995; Aston-Jones et al., 2004), whose influences could be subject to alteration by our immunotoxin lesions. This possibility was tested in rats subjected to acute restraint after receiving excitotoxin or sham lesions of the mPFCd ( $n=3$ per group) (Radley et al., 2006). No significant difference was observed in comparing stress-induced Fos expression in LC of sham $(333 \pm 45$ Fos+DBH-labeled cells) versus excitotoxin-lesioned $(309 \pm 27)$ groups $(t=0.5$; $p=0.7)$. These findings further support the view that the effects of cortical immunotoxin injection on HPA output result from a loss of stress-sensitive LC neurons in LC that project to MPFC.

\section{Discussion}

Targeted disruption of noradrenergic LC projections to the mPFCd resulted in enhanced activational responses to acute restraint stress in this cortical region, whereas independent measures of HPA output were attenuated. Cellular activation in dorsal, but not ventral, mPFC was inversely related to the degree of stress-induced recruitment of PVH neurons across experimental conditions. The present findings thus localize previously documented HPA-facilitatory influences of LC, at least in part, to its projections to mPFCd and help to clarify the extended circuitry underlying mPFC modulation of HPA responses to acute emotional stress.

\section{Methodological considerations}

Previous studies endorse anti-DBH-saporin as a tool for achieving focal aminergic denervation by ablating the neurons that project to targeted terminal fields (Ritter et al., 2003; Schiltz and Sawchenko, 2007). The approach exploits the fact that DBH on the inner surface of synaptic vesicles is exposed to the extracellular space during transmitter release, providing a target for antiserum to bind the enzyme, and toxin to be internalized, in the normal course of vesicle recycling (Wrenn et al., 1996). DBH is required for the synthesis of both norepinephrine and epinephrine, but the $\mathrm{MPFC}$ is not known to receive an adrenergic innervation (Morrison et al., 1979; Hokfelt et al., 1984). This, coupled with evidence from axonal transport and lesion studies identifying the LC as the sole source of the isocortical noradrenergic innervation (Morrison et al., 1981), allows specific targeting of noradrenergic inputs in this instance. Supporting the specificity of denervation were observations that the dopaminergic $\left(\mathrm{TH}^{+} /\right.$ $\mathrm{DBH}^{-}$) innervation of $\mathrm{mPFC}$ was ostensibly unaffected in the face of profound loss of DBH-positive projections (Milstein et al., 2007). This contrasts with catecholamine neurotoxins that target both noradrenergic and dopaminergic neurons (Jonsson, 1980).

In addition to producing near-complete denervation of the (targeted) mPFCd, immunotoxin treatment resulted in partial noradrenergic deafferentation of some adjoining cortical areas. 

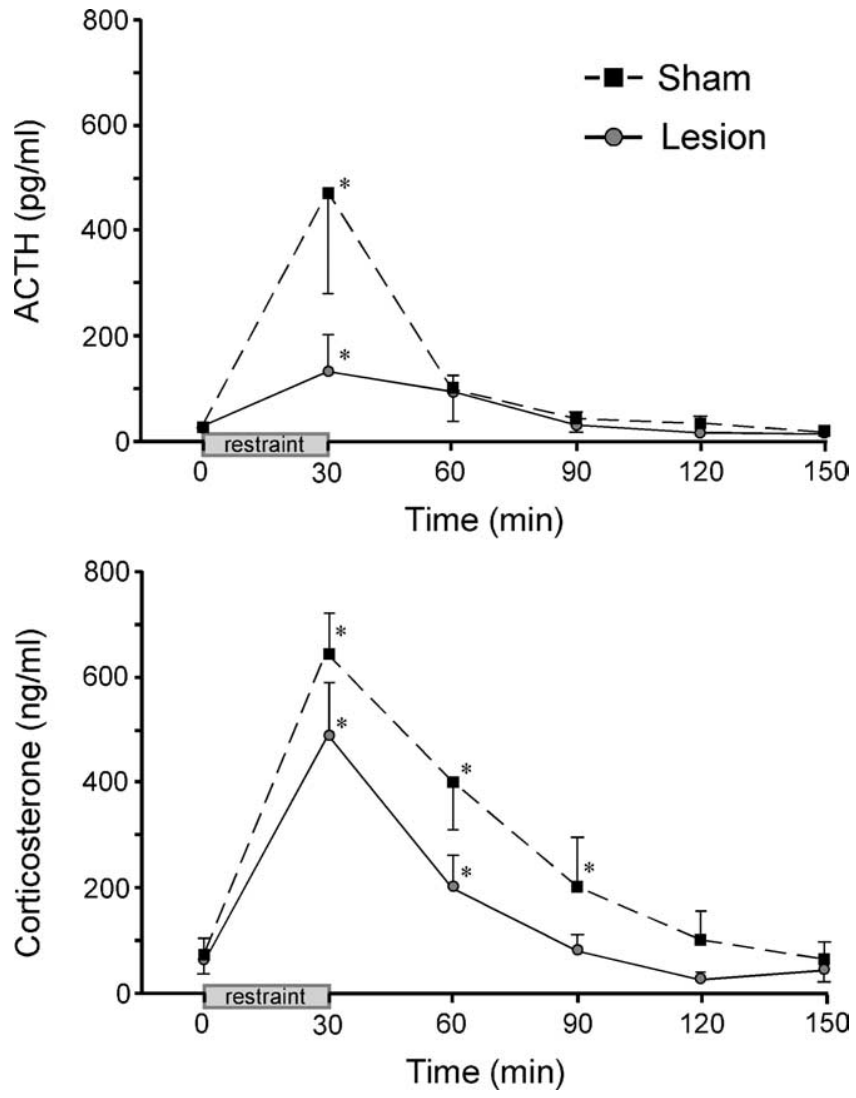

Figure 5. Noradrenergic denervation of mPFCd attenuates pituitary-adrenal secretory responses to acute restraint. Mean \pm SEM plasma ACTH (top) and corticosterone (bottom) levels in sham and immunotoxin-injected animals before $(0 \mathrm{~min})$ and at varying intervals after acute restraint exposure. Stress exposure significantly increased plasma levels of both hormones in both sham- and immunotoxin-lesioned animals. Although mean values did not differ reliably at any poststress time point ( $p$ values $>0.05$ ), the overall integrated response of each hormone of the lesion group (areas under the curve) was significantly lower than those of sham controls (see Results). ${ }^{*} p<0.05$, differs significantly from basal $(0 \mathrm{~min}$ ) values from within each group. $n=$ 5 per group.

Most affected were regions immediately adjoining the site of injection in PL, consistent with analyses of collateralization in this pathway (Loughlin et al., 1982). In this context, it is important to note that, although pronounced alterations in stress-induced Fos expression were evident in the profoundly denervated target zone (PL), responses of an adjoining and partially denervated field (IL) were not significantly affected. Finally, subcortical structures innervated by the LC showed little or no evidence of denervation after immunotoxin injections in mPFCd, which is consistent with work showing that LC comprises topographically organized subsets of neurons that give rise to distinctive projections (Mason and Fibiger, 1979; Loughlin et al., 1982).

\section{The mPFC and HPA modulation}

Beginning with the seminal work of Diorio et al. (1993), several lesion studies have sought to characterize mPFC influences on HPA and other stress-related endpoints. The weight of evidence suggests that these influences are inhibitory (Diorio et al., 1993; Brake et al., 2000; Figueiredo et al., 2003; Spencer et al., 2005), although dissenting findings have been published (Jinks and McGregor, 1997; Sullivan and Gratton, 1999). We recently offered a basis for reconciling these discrepancies in showing that lesions of $\mathrm{mPFCd}$ (centered in PL) robustly enhance, whereas lesions of ventral mPFC (mPFCv) (centered in IL) mildly atten-
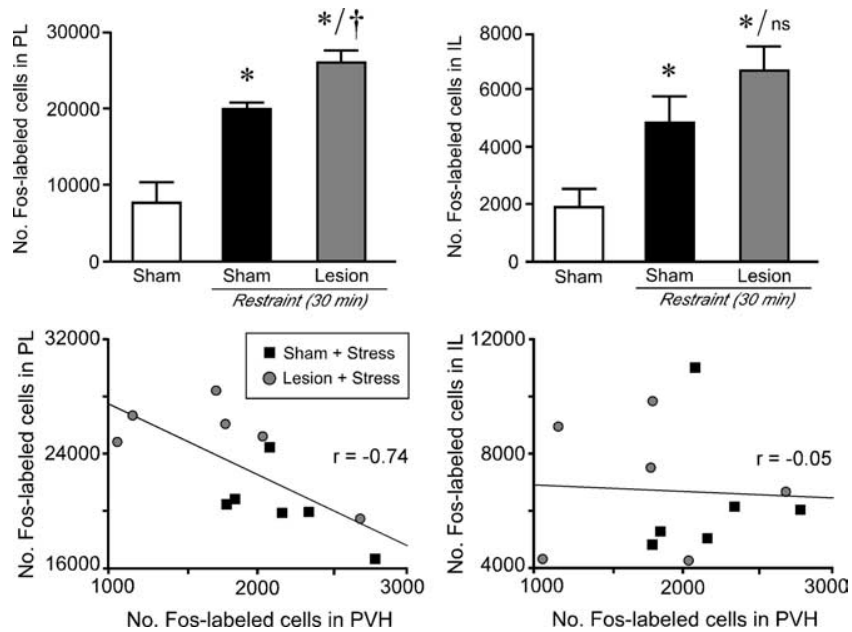

Figure 6. Acute stress-induced activational responses of $\mathrm{mPFC}$ and PVH are inversely correlated. Top, Mean + SEM number of Fos-immunoreactive neurons in dorsal (PL; left) and ventral (IL; right) parts of the $\mathrm{mPFC}$ as a function of treatment status. Exposure to a single $30 \mathrm{~min}$ restraint session results in an increased number of Fos-immunoreactive neurons in PL, which was reliably enhanced in animals receiving immunotoxin lesions of $\mathrm{mPFCd}$. No such effect of immunotoxin lesions was seen in IL. ${ }^{*} p<0.05$, differs significantly from unstressed controls; ${ }^{\dagger} p<0.05$, differs significantly from sham-lesioned stressed animals. $n=6$ per group. Bottom, Relationship between Fos activational responses in $\mathrm{MPFC}$ subdivisions, PL and IL, as a function of Fos activation in the PVH after acute restraint stress. Plots of individual values from sham- and immunotoxin-lesioned animals subjected to a single $30 \mathrm{~min}$ restraint session indicated that the degree of Fos activation in PL is inversely correlated with that in the PVH $(r=-0.71 ; p<$ $0.05)$. In contrast, there is no reliable correlation between Fos activation in IL and PVH ( $r=$ $-0.05 ; p=0.9$ ).

uate, HPA responses to acute restraint (Radley et al., 2006). Although the circuitry that provides for mPFCd inhibition of $\mathrm{PVH}$ output has not been established (Fig. 8), it likely involves an intervening GABAergic relay, localized in cell groups closely adjoining the PVH (Roland and Sawchenko, 1993; Boudaba et al., 1996) and/or in the bed nucleus of the stria terminalis (Choi et al., 2007). The necessity of an interposed inhibitory relay is consistent with evidence that extrinsic mPFC projections are predominantly glutamatergic (Ottersen et al., 1995) and distribute diffusely to the candidate relay sites noted above, but not to the PVH proper (Sesack et al., 1989; Hurley et al., 1991; Vertes, 2004). The present findings identify LC projections to mPFCd as an upstream component of this system.

\section{The place of the LC in HPA control circuitry}

The LC plays recognized roles in arousal and behavioral activation in response to a range of alerting stimuli (Berridge and Waterhouse, 2003). Electrophysiologic activity and immediate-early gene responses of LC neurons are enhanced by exposure to a variety of acute emotional stressors, as is NE release in $\mathrm{mPFC}$ (Abercrombie and Jacobs, 1987; Ceccatelli et al., 1989; Cullinan et al., 1995; Palkovits et al., 1997; Passerin et al., 2000). In line with this, previous inactivation studies suggest an overall facilitatory influence of LC on emotional stress-induced HPA activation. One group found that pharmacologic silencing of LC abolished acute foot-shock-induced cellular activation of the $\mathrm{PVH}$ (Passerin et al., 2000), whereas another described attenuation of restraint-induced corticosterone, but not $\mathrm{ACTH}$, secretion after 6-hydroxydopamine lesions of LC (Ziegler et al., 1999).

Our findings support previous reports that the LC facilitates adaptive responses to emotional stress and refine them in several ways. First, they indicate that the HPA-facilitatory influence of 

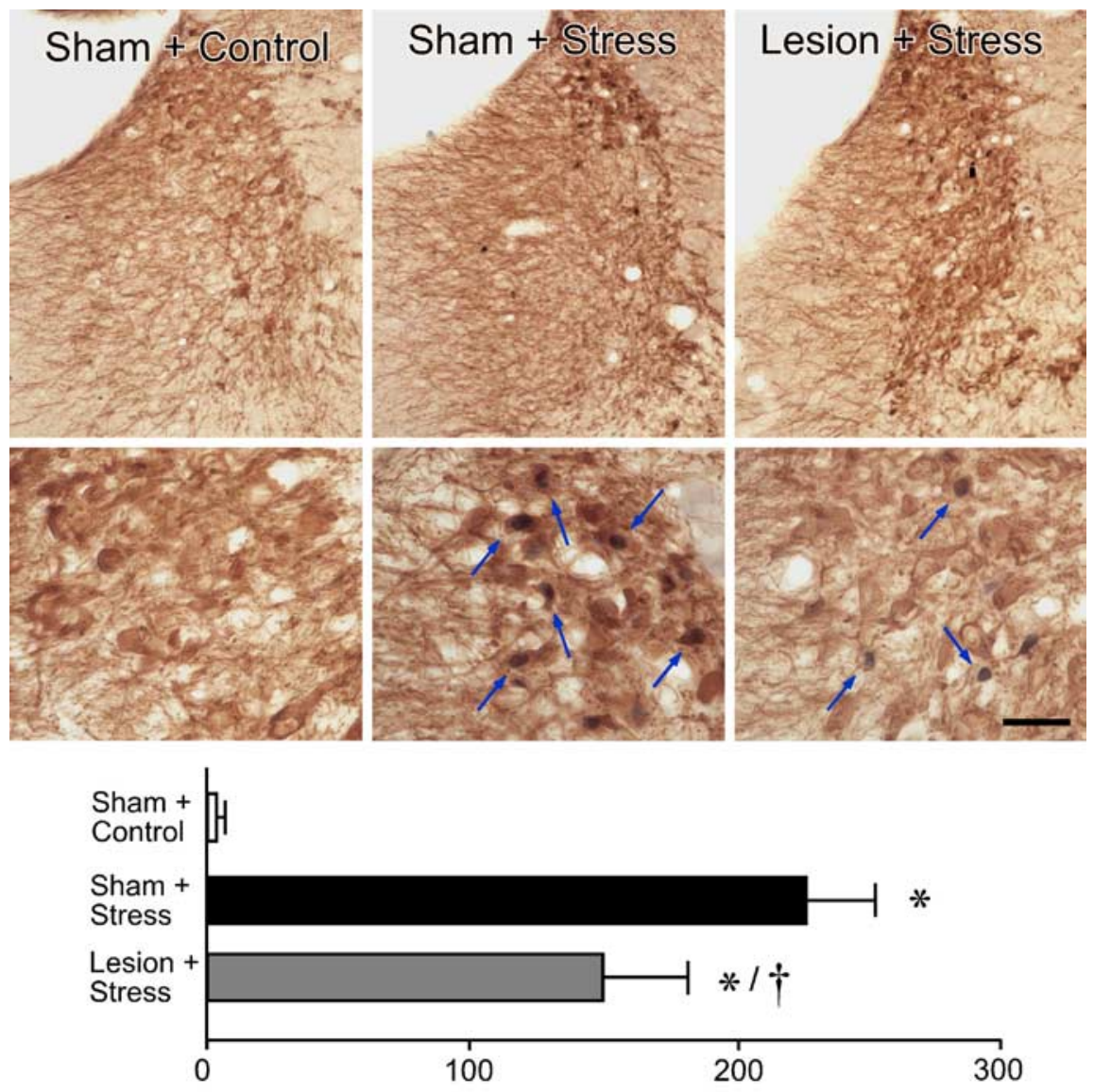

No. activated (Fos) noradrenergic (DBH) neurons in LC

Figure 7. Effects of immunotoxin on stress-induced activational responses in the LC. Top, middle, Lower- and highermagnification bright-field photomicrographs showing Fos-immunoreactive (black nuclei) and DBH-immunoreactive (brown cytoplasm) labeling in $\mathrm{LC}$ as a function of treatment. Relative to sham-lesioned, unstressed controls, restraint stress (30 min) results in a marked increase in Fos expression in DBH-labeled noradrenergic neurons in LC. In contrast, animals with immunotoxin lesions of mPFCd show an attenuation of stress-induced Fos immunoreactivity in LC noradrenergic neurons. Arrows mark examples of double-labeled neurons. Bottom, Mean \pm SEM number of double-labeled neurons in treatment groups. Although there is almost a complete absence of Fos activation in sham-lesioned, unstressed animals, stress results in a significant activation, and anti-DBH-saporin lesions attenuate the responsiveness of DBH-stained $\mathrm{LC}$ neurons. The degree of reduction ( $37 \%)$ is similar to the extent of immunotoxin-induced cell loss (23\%). ${ }^{*} p<0.01$, differs significantly from sham-lesioned unstressed animals; ${ }^{\dagger} p<$ 0.05 , differs significantly from sham-lesioned stressed animals. Average of $n=4$ per group. Scale bar: top row, $125 \mu \mathrm{m}$; bottom row, $50 \mu \mathrm{m}$.

the LC is mediated, at least in part, via the mPFCd. This conclusion is supported by the fact, that although the $\mathrm{PVH}$ receives a substantial catecholaminergic innervation, the LC contributes minimally to this (Sawchenko and Swanson, 1981, 1982; Cunningham and Sawchenko, 1988). Furthermore, the direct aminergic innervation of PVH is implicated in HPA responses to physiological, but not emotional, stressors (Ericsson et al., 1994; Li et al., 1996; Schiltz and Sawchenko, 2007), whereas the LC is more generally responsive to emotional stress (Sved et al., 2002). Second, the results support a modulatory, and not a mediating, role for LC in stress-induced HPA activation. This derives from the observation that disruption of the LC-mPFCd pathway attenuated, but did not completely block, HPA responses to acute restraint. Finally, they indicate that HPA-facilitatory influences of LC are exerted during stress, because noradrenergic deafferentation of mPFCd did not affect basal levels of Fos expression or stress hormones. Although lesion effects on resting CRF mRNA levels were not examined here, we reported previously that these were not altered after more encompassing (excitoxin) mPFCd lesions (Radley et al., 2006).

The idea that the LC serves normally to facilitate HPA responses to emotional stressors via the mPFCd seems at first blush to be at odds with the substantial evidence (see above) that mPFCd inhibits PVH drive to the axis. It can be accommodated, however, if the net effect of engaging the LC during stress on mPFC output is inhibitory. Our observation that noradrenergic deafferentation resulted in a marked increase in the number of neurons in $\mathrm{mPFCd}$ (but not mPFCv) exhibiting stress-induced Fos expression is consistent with this view, as is the significant inverse correlation between Fos responses in PL (but not IL) and $\mathrm{PVH}$, independent of lesion status. Overall, our findings support the conclusion that the net effect of LC activation during stress is disinhibitory to activation of HPA output, an effect mediated at least partly via inhibition of mPFCd (Fig. 8).

Plausible mechanisms by which norepinephrine might inhibit mPFC output during stressful situations have been suggested (for review, see Ramos and Arnsten, 2007). Under basal conditions, NE effects in mPFC appear to be mediated predominantly via high-affinity $\alpha 2 \mathrm{~A}$ adrenoceptors coupled to $G_{i}$ and inhibition of adenylate cyclase that facilitate prefrontal network activity by inhibiting hyperpolarizationactivated cyclic nucleotide-gated cation ( $\mathrm{HCN})$ channels on the dendrites of pyramidal neurons (Ramos and Arnsten, 2007). During stress, enhanced NE release results in engagement of lower-affinity $\alpha 1$ adrenoceptors (linked to $\mathrm{G}_{\mathrm{q}}$ and phosphatidyl inositol signaling), and perhaps $\beta$ adrenoceptors (positively coupled to $\mathrm{G}_{\mathrm{s}}$ and adenylate cyclase), resulting in enhanced $\mathrm{HCN}$ signaling and inhibition of neuronal firing. These mechanisms have been implicated most clearly in the stress-induced impairment of prefrontaldependent behaviors, such as working memory and attentional set shifting (Birnbaum et al., 1999; Liston et al., 2006). They could also explain the enhancement of stress-induced Fos expression observed in the mPFC deprived of its noradrenergic innervation and thus seem likely to generalize to HPA control.

\section{General implications}

In addition to participating in the regulation of stress responses, the mPFC is also a target of them. Repeated exposure to emotional stress gives rise to dendritic atrophy and synapse loss in this region (Radley et al., 2004, 2008; Brown et al., 2005; Cerqueira et al., 2007; Liu and Aghajanian, 2008), findings that have clinical parallels in reports of mPFC shrinkage and functional impairment in posttraumatic stress disorder (PTSD) (Rauch et al., 2003; Yamasue et al., 2003; Shin et al., 2005, 2007). Norepinephrine has been linked to the mediation of maladaptive, as well as adaptive, consequences of stress exposure (Zigmond et al., 1995), being 
implicated in psychiatric conditions including PTSD (Bremner et al., 1997; Southwick et al., 1999), depression, and attention deficit hyperactivity disorder (Callado et al., 1998; Biederman and Spencer, 1999). Drugs that modulate noradrenergic transmission have demonstrated efficacy in treating such mood disorders via actions that may be exerted, at least in part, on the mPFC (Frazer, 2000; Michelson et al., 2003; Raskind et al., 2003). Additional progress in unraveling the broader circuitry governing HPA responses to emotional stress, and the places of the LC and mPFC within it, should foster more informed management of stress-related psychiatric conditions.

\section{References}

Abercrombie ED, Jacobs BL (1987) Single-unit response of noradrenergic neurons in the locus coeruleus of freely moving cats. I. Acutely presented stressful and nonstressful stimuli. J Neurosci 7:2837-2843.

Abercrombie M (1949) Estimation of nuclear populations from microtome populations sections. Anat Rec 94:239-247.

Antoni G (1986) Hypothalamic control of adrenocorticotropin secretion: advances since the discovery of 41-residue corticotropin-releasing factor. Endocr Rev 7:351-378.

Aston-Jones G, Rajkowski J, Kubiak P, Valentino RJ, Shipley MT (1996) Role of the locus coeruleus in emotional activation. Prog Brain Res 107:379-402.

Aston-Jones G, Rajkowski J, Cohen J (2000) Locus coeruleus and regulation of behavioral flexibility and attention. Prog Brain Res 126:165-182.

Aston-Jones G, Zhu Y, Card JP (2004) Numerous GABAergic afferents to locus ceruleus in the pericerulear dendritic zone: possible interneuronal pool. J Neurosci 24:2313-2321.

Berridge CW, Waterhouse BD (2003) The locus coeruleus-noradrenergic system: modulation of behavioral state and state-dependent cognitive processes. Brain Res Brain Res Rev 42:33-84.

Biederman J, Spencer T (1999) Attention-deficit/hyperactivity disorder (ADHD) as a noradrenergic disorder. Biol Psychiatry 46:1234-1242.

Birnbaum SG, Gobeske KT, Auerbach J, Taylor JR, Arnsten AF (1999) A role for norepineprhine in stress-induced cognitive deficits: alpha-1adrenoceptor mediation in prefrontal cortex. Biol Psychiatry 46:1266-1274.

Boudaba C, Szabo K, Tasker JG (1996) Physiological mapping of local inhibitory inputs to the hypothalamic paraventricular nucleus. J Neurosci 16:7151-7160.

Brake WG, Flores G, Francis D, Meaney MJ, Srivastava LK, Gratton A (2000) Enhanced nucleus accumbens dopamine and plasma corticosterone stress responses in adult rats with neonatal excitotoxic lesions to the medial prefrontal cortex. Neuroscience 96:687-695.

Bremner JD, Innis RB, Ng CK, Staib LH, Salomon RM, Bronen RA, Duncan J, Southwick SM, Krystal JH, Rich D, Zubal G, Dey H, Soufer R, Charney DS (1997) Positron emission tomography measurement of cerebral metabolic correlates of yohimbine administration in combat-related posttraumatic stress disorder. Arch Gen Psychiatry 54:246-254.

Brown SM, Henning S, Wellman CL (2005) Mild, short-term stress alters dendritic morphology in rat medial prefrontal cortex. Cereb Cortex 15:1714-1722.

Bush G, Luu P, Posner MI (2000) Cognitive and emotional influences in anterior cingulate cortex. Trends Cogn Sci 4:215-222.

Callado LF, Meana JJ, Grijalba B, Pazos A, Sastre M, Garcia-Sevilla JA (1998) Selective increase of alpha2A-adrenoceptor agonist binding sites in brains of depressed suicide victims. J Neurochem 70:1114-1123.

Ceccatelli S, Villar MJ, Goldstein M, Hokfelt T (1989) Expression of c-Fos

immunoreactivity in transmitter-characterized neurons after stress. Proc Natl Acad Sci USA 86:9569-9573.

Cerqueira JJ, Mailliet F, Almeida OF, Jay TM, Sousa N (2007) The prefrontal cortex as a key target of the maladaptive response to stress. J Neurosci 27:2781-2787.

Choi DC, Furay AR, Evanson NK, Ostrander MM, Ulrich-Lai YM, Herman JP (2007) Bed nucleus of the stria terminalis subregions differentially regulate hypothalamic-pituitary-adrenal axis activity: implications for the integration of limbic inputs. J Neurosci 27:2025-2034.

Cullinan WE, Herman JP, Battaglia DF, Akil H, Watson SJ (1995) Pattern and time course of immediate early gene expression in rat brain following acute stress. Neuroscience 64:477-505.

Cunningham Jr ET, Sawchenko PE (1988) Anatomical specificity of noradrenergic inputs to the paraventricular and supraoptic nuclei of the rat hypothalamus. J Comp Neurol 274:60-76.

Diorio D, Viau V, Meaney MJ (1993) The role of the medial prefrontal cortex (cingulate gyrus) in the regulation of hypothalamic-pituitaryadrenal responses to stress. J Neurosci 13:3839-3847.

Ericsson A, Kovacs KJ, Sawchenko PE (1994) A functional anatomical analysis of central pathways subserving the effects of interleukin-1 on stressrelated neuroendocrine neurons. J Neurosci 14:897-913.

Figueiredo HF, Bruestle A, Bodie B, Dolgas CM, Herman JP (2003) The medial prefrontal cortex differentially regulates stress-induced c-fos expression in the forebrain depending on type of stressor. Eur J Neurosci $18: 2357-2364$.

Frazer A (2000) Norepinephrine involvement in antidepressant action. J Clin Psychiatry 61 [Suppl 10]:25-30.

Gundersen HJ, Bendtsen TF, Korbo L, Marcussen N, Møller A, Nielsen K, Nyengaard JR, Pakkenberg B, Sørensen FB, Vesterby A, West MJ (1988) Some new, simple and efficient stereological methods and their use in pathological research and diagnosis. APMIS 96:379-394.

Hokfelt T, Johansson O, Goldstein M (1984) Central catecholamine neurons as revealed by immunohistochemistry with special reference to adrenaline neurons. Amsterdam: Elsevier.

Hurley KM, Herbert H, Moga MM, Saper CB (1991) Efferent projections of the infralimbic cortex of the rat. J Comp Neurol 308:249-276.

Jinks AL, McGregor IS (1997) Modulation of anxiety-related behaviours following lesions of the prelimbic or infralimbic cortex in the rat. Brain Res 772:181-190. 
Jonsson G (1980) Chemical neurotoxins as denervation tools in neurobiology. Annu Rev Neurosci 3:169-187.

Kerns JG, Cohen JD, MacDonald III AW, Cho RY, Stenger VA, Carter CS (2004) Anterior cingulate conflict monitoring and adjustments in control. Science 303:1023-1026.

Krettek JE, Price JL (1977) Projections from the amygdaloid complex to the cerebral cortex and thalamus in the rat and cat. J Comp Neurol 172:687-722.

Li HY, Ericsson A, Sawchenko PE (1996) Distinct mechanisms underlie activation of hypothalamic neurosecretory neurons and their medullary catecholaminergic afferents in categorically different stress paradigms. Proc Natl Acad Sci USA 93:2359-2364.

Liu RJ, Aghajanian GK (2008) Stress blunts serotonin- and hypocretinevoked EPSCs in prefrontal cortex: role of corticosterone-mediated apical dendritic atrophy. Proc Natl Acad Sci USA 105:359-364.

Liston C, Miller MM, Goldwater DS, Radley JJ, Rocher AB, Hof PR, Morrison JH, McEwen BS (2006) Stress-induced alterations in prefrontal cortical dendritic morphology predict selective impairments in perceptual attentional set-shifting. J Neurosci 26:7870-7874.

Loughlin SE, Foote SL, Fallon JH (1982) Locus coeruleus projections to cortex: topography, morphology and collateralization. Brain Res Bull 9:287-294.

Luppi PH, Aston-Jones G, Akaoka H, Chouvet G, Jouvet M (1995) Afferent projections to the rat locus coeruleus demonstrated by retrograde and anterograde tracing with cholera-toxin B subunit and Phaseolus vulgaris leucoagglutinin. Neuroscience 65:119-160.

Mason ST, Fibiger HC (1979) Regional topography within noradrenergic locus coeruleus as revealed by retrograde transport of horseradish peroxidase. J Comp Neurol 187:703-724.

Michelson D, Adler L, Spencer T, Reimherr FW, West SA, Allen AJ, Kelsey D, Wernicke J, Dietrich A, Milton D (2003) Atomoxetine in adults with ADHD: two randomized, placebo-controlled studies. Biol Psychiatry 53:112-120.

Milstein JA, Lehmann O, Theobald DE, Dalley JW, Robbins TW (2007) Selective depletion of cortical noradrenaline by anti-dopamine betahydroxylase-saporin impairs attentional function and enhances the effects of guanfacine in the rat. Psychopharmacology (Berl) 190:51-63.

Morilak DA, Barrera G, Echevarria DJ, Garcia AS, Hernandez A, Ma S, Petre CO (2005) Role of brain norepinephrine in the behavioral response to stress. Prog Neuropsychopharmacol Biol Psychiatry 29:1214-1224.

Morrison JH, Molliver ME, Grzanna R (1979) Noradrenergic innervation of cerebral cortex: widespread effects of local cortical lesions. Science 205:313-316.

Morrison JH, Molliver ME, Grzanna R, Coyle JT (1981) The intra-cortical trajectory of the coeruleo-cortical projection in the rat: a tangentially organized cortical afferent. Neuroscience 6:139-158.

Ottersen OP, Hjelle OP, Osen KK, Laake JH (1995) Amino acid transmitters, Ed 2. San Diego: Academic.

Palkovits M, Baffi JS, Pacak K (1997) Stress-induced Fos-like immunoreactivity in the pons and the medulla oblongata of rats. Stress 1:155-168.

Passerin AM, Cano G, Rabin BS, Delano BA, Napier JL, Sved AF (2000) Role of locus coeruleus in foot shock-evoked Fos expression in rat brain. Neuroscience 101:1071-1082.

Radley JJ, Sawchenko PE (2007) Noradrenergic inputs into dorsal medial prefrontal cortex (mPFC) modulate paraventricular hypothalamic responses to acute restraint stress. Soc Neurosci Abstr 33:198.194.

Radley JJ, Sisti HM, Hao J, Rocher AB, McCall T, Hof PR, McEwen BS, Morrison JH (2004) Chronic behavioral stress induces apical dendritic reorganization in pyramidal neurons of the medial prefrontal cortex. Neuroscience 125:1-6.

Radley JJ, Arias CM, Sawchenko PE (2006) Regional differentiation of the medial prefrontal cortex in regulating adaptive responses to acute emotional stress. J Neurosci 26:12967-12976.

Radley JJ, Rocher AB, Rodriguez A, Ehlenberger DB, Dammann M, McEwen BS, Morrison JH, Wearne SL, Hof PR (2008) Repeated stress alters dendritic spine morphology in the rat medial prefrontal cortex. J Comp Neurol 507:1141-1150.

Ramos BP, Arnsten AF (2007) Adrenergic pharmacology and cognition: focus on the prefrontal cortex. Pharmacol Ther 113:523-536.

Raskind MA, Peskind ER, Kanter ED, Petrie EC, Radant A, Thompson CE, Dobie DJ, Hoff D, Rein RJ, Straits-Troster K, Thomas RG, McFall MM (2003) Reduction of nightmares and other PTSD symptoms in combat veterans by prazosin: a placebo-controlled study. Am J Psychiatry 160:371-373.

Rauch SL, Shin LM, Segal E, Pitman RK, Carson MA, McMullin K, Whalen PJ, Makris N (2003) Selectively reduced regional cortical volumes in post-traumatic stress disorder. NeuroReport 14:913-916.

Ritter S, Bugarith K, Dinh TT (2001) Immunotoxic destruction of distinct catecholamine subgroups produces selective impairment of glucoregulatory responses and neuronal activation. J Comp Neurol 432:197-216.

Ritter S, Watts AG, Dinh TT, Sanchez-Watts G, Pedrow C (2003) Immunotoxin lesion of hypothalamically projecting norepinephrine and epinephrine neurons differentially affects circadian and stressor-stimulated corticosterone secretion. Endocrinology 144:1357-1367.

Roland BL, Sawchenko PE (1993) Local origins of some GABAergic projections to the paraventricular and supraoptic nuclei of the hypothalamus in the rat. J Comp Neurol 332:123-143.

Sawchenko PE, Swanson LW (1981) Central noradrenergic pathways for the integration of hypothalamic neuroendocrine and autonomic responses. Science 214:685-687.

Sawchenko PE, Swanson LW (1982) The organization of noradrenergic pathways from the brainstem to the paraventricular and supraoptic nuclei in the rat. Brain Res 257:275-325.

Sawchenko PE, Cunningham Jr ET, Mortrud MT, Pfeiffer SW, Gerfen CR (1990) Phaseolus vulgaris-leucoagglutanin (PHA-L) anterograde axonal transport technique. Methods Neurosci 3:247-260.

Schiltz JC, Sawchenko PE (2002) Distinct brain vascular cell types manifest inducible cyclooxygenase expression as a function of the strength and nature of immune insults. J Neurosci 22:5606-5618.

Schiltz JC, Sawchenko PE (2007) Specificity and generality of the involvement of catecholaminergic afferents in hypothalamic responses to immune insults. J Comp Neurol 502:455-467.

Schmitz C, Hof PR (2000) Recommendations for straightforward and rigorous methods of counting neurons based on a computer simulation approach. J Chem Neuroanat 20:93-114.

Sesack SR, Deutch AY, Roth RH, Bunney BS (1989) Topographical organization of the efferent projections of the medial prefrontal cortex in the rat: an anterograde tract-tracing study with Phaseolus vulgaris leucoagglutinin. J Comp Neurol 290:213-242.

Shin LM, Bush G, Whalen PJ, Handwerger K, Cannistraro PA, Wright CI, Martis B, Macklin ML, Lasko NB, Orr SP, Pitman RK, Rauch SL (2007) Dorsal anterior cingulate function in posttraumatic stress disorder. J Trauma Stress 20:701-712.

Shin LM, Wright CI, Cannistraro PA, Wedig MM, McMullin K, Martis B, Macklin ML, Lasko NB, Cavanagh SR, Krangel TS, Orr SP, Pitman RK, Whalen PJ, Rauch SL (2005) A functional magnetic resonance imaging study of amygdala and medial prefrontal cortex responses to overtly presented fearful faces in posttraumatic stress disorder. Arch Gen Psychiatry 62:273-281.

Shu SY, Ju G, Fan LZ (1988) The glucose oxidase-DAB-nickel method in peroxidase histochemistry of the nervous system. Neurosci Lett 85:169-171.

Simmons DM, Arriza JL, Swanson LW (1989) A complete protocol for in situ hybridization of messenger RNAs in brain and other tissues with radiolabeled single-stranded RNA probes. J Histotechnol 12:169-181.

Southwick SM, Bremner JD, Rasmusson A, Morgan III CA, Arnsten A, Charney DS (1999) Role of norepinephrine in the pathophysiology and treatment of posttraumatic stress disorder. Biol Psychiatry 46:1192-1204.

Spencer SJ, Buller KM, Day TA (2005) Medial prefrontal cortex control of the paraventricular hypothalamic nucleus response to psychological stress: possible role of the bed nucleus of the stria terminalis. J Comp Neurol 481:363-376.

Sullivan RM, Gratton A (1999) Lateralized effects of medial prefrontal cortex lesions on neuroendocrine and autonomic stress responses in rats. J Neurosci 19:2834-2840.

Sved AF, Cano G, Passerin AM, Rabin BS (2002) The locus coeruleus, Barrington's nucleus, and neural circuits of stress. Physiol Behav 77: 737-742.

Swanson LW, Kuypers HG (1980) The paraventricular nucleus of the hypothalamus: cytoarchitectonic subdivisions and organization of projections to the pituitary, dorsal vagal complex, and spinal cord as demonstrated by retrograde fluorescence double-labeling methods. J Comp Neurol 194:555-570. 
Vaughan JM, Rivier J, Corrigan AZ, McClintock R, Campen CA, Jolley D, Voglmayr JK, Bardin CW, Rivier C, Vale W (1989) Detection and purification of inhibin using antisera generated against synthetic peptide fragments. Methods Enzymol 168:588-617.

Vertes RP (2004) Differential projections of the infralimbic and prelimbic cortex in the rat. Synapse 51:32-58.

Viau V, Sawchenko PE (2002) Hypophysiotropic neurons of the paraventricular nucleus respond in spatially, temporally, and phenotypically differentiated manners to acute vs. repeated restraint stress: rapid publication. J Comp Neurol 445:293-307.

Vogt BA, Peters A (1981) Form and distribution of neurons in rat cingulate cortex: areas 32, 24, and 29. J Comp Neurol 195:603-625.

Wrenn CC, Picklo MJ, Lappi DA, Robertson D, Wiley RG (1996) Central noradrenergic lesioning using anti-DBH-saporin: anatomical findings. Brain Res 740:175-184.

Yamasue H, Kasai K, Iwanami A, Ohtani T, Yamada H, Abe O, Kuroki N, Fukuda R, Tochigi M, Furukawa S, Sadamatsu M, Sasaki T, Aoki S, Ohtomo K, Asukai N, Kato N (2003) Voxel-based analysis of MRI reveals anterior cingulate gray-matter volume reduction in posttraumatic stress disorder due to terrorism. Proc Natl Acad Sci USA 100:9039-9043.

Ziegler DR, Cass WA, Herman JP (1999) Excitatory influence of the locus coeruleus in hypothalamic-pituitary-adrenocortical axis responses to stress. J Neuroendocrinol 11:361-369.

Zigmond MJ, Finlay JM, Sved AF (1995) Neurochemical studies in central noradrenergic responses to acute and chronic stress. Philadelphia: Lippencott-Raven. 